\title{
PHOTOLYSIS AND ADVANCED OXIDATION TREATMENT OF PHARMACEUTICALS IN TAP WATER AND TREATED SEWAGE
}

\author{
Kamilla Hansen ${ }^{\prime}$ \\ Henrik R. Andersen' \\ Tina Kosjek ${ }^{2}$ \\ Ester Heath ${ }^{2}$ \\ Povl Kaas ${ }^{3}$ \\ Anna Ledin ${ }^{4}$ \\ ${ }^{\prime}$ Technical University of Denmark, Denmark \\ 'Jožef Stefan Institute, Slovenia \\ ${ }^{3}$ Scan Research A/S, Denmark \\ ${ }^{4}$ Linköping University, Sweden
}

\begin{abstract}
The aim of this study was to investigate the removal efficiency of six pharmaceuticals by photo-degradation and the advanced oxidation process (AOP), $U V / \mathrm{H}_{2} \mathrm{O}_{2}$. The six pharmaceuticals were the four NSAIDs ibuprofen, diclofenac, naproxen and ketoprofen, the pharmacological active metabolite of the lipid lowering agent, clofibrin, clofibric acid, and the anticonvulsant and mood stabilizing drug, carbamazepine.

Treatment experiments were performed using a UV lamp optimized for photochemical treatment in a flow through set-up. For the AOP experiments $60 \mathrm{mg} / \mathrm{L} \mathrm{H}_{2} \mathrm{O}_{2}$ was added to the water before treatment. The treatment effectiveness is evaluated based on the Electrical Energy per Order (EEO) (unit $\mathrm{kWh} / \mathrm{m}^{3}$ ), which is defined as the electrical energy consumed per unit volume of water treated required for $90 \%$ removal of the investigated compound.

It was found that four of the six pharmaceuticals were completely removed in tap water by both UV treatment and the AOP. The exceptions were ibuprofen and carbamazepine, which exhibited a relationship between UV dose and removal. The electrical energy per order, EEO was determined to $8.2 \mathrm{kWh} / \mathrm{m}^{3}(\mathrm{UV})$ and $3.7 \mathrm{kWh} / \mathrm{m}^{3}\left(\mathrm{UV} / \mathrm{H}_{2} \mathrm{O}_{2}\right)$ for ibuprofen.

In the wastewater effluent the removal by UV irradiation was almost complete for ketoprofen, while the other compounds show dependency of flow rate/UV dose. Ibuprofen was the compound that needed the highest UV dose to remove $90 \%\left(\mathrm{EEO}=33.4 \mathrm{kWh} / \mathrm{m}^{3}\right)$ where naproxen and clofibric acid required $9.6 \mathrm{kWh} / \mathrm{m}^{3}$ and $5.5 \mathrm{kWh} / \mathrm{m}^{3}$, respectively. Ketoprofen and diclofenac needed considerable less energy than clofibric acid. Ibuprofen and naproxen is biodegradable and will be removed in biologically treated wastewater. Therefore, the relevant estimate of the needed treatment is the energy use for removal of clofibric acid which required $5.5 \mathrm{kWh} / \mathrm{m}^{3}$ for $90 \%$ removal.
\end{abstract}

\section{KEYWORDS}

Pharmaceuticlas; UV; AOP; Electrical Energy per Order. 


\section{INTRODUCTION}

Few pharmaceuticals are not removed in conventional sewage treatment, among the most important of these in terms of high consumption volume are carbamazepine [1], clofibric acid [2] and diclofenac $[1,2]$. It is known that the above mentioned three stable pharmaceuticals can be photo-degraded in surface waters by sunlight $[3,4]$. This is likely the most important ultimate fate of non bio-degradable and non-sorbing pharmaceuticals.

The UV-absorption spectra of carbamazepine and clofibric acid [3] shows that carbamazepine absorbs from $320 \mathrm{~nm}$ with a local maximum at $280 \mathrm{~nm}$. Clofibric acid absorbs weakly between $300-240$ and has a local maximum at $230 \mathrm{~nm}$. Sunlight has very little intensity below $280 \mathrm{~nm}$ and even most sunlight below $400 \mathrm{~nm}$ is filtered by the atmosphere. UV lamps used e.g. for photo-chemicals reactions and disinfection of water can create a many fold more intensively illumination of water with a higher fractions of light having lower wavelengths thus potentially decreasing half lives of pharmaceuticals to the seconds time scale.

The aim of this study was to investigate the removal efficiency of six pharmaceuticals by photo-degradation and the advanced oxidation process (AOP), $U V / \mathrm{H}_{2} \mathrm{O}_{2}$. The six pharmaceuticals were the four non-steroidal-anti-inflamatory drugs: ibuprofen, diclofenac, naproxen and ketoprofen, the pharmacological active metabolite of the lipid lowering agent, clofibrin, clofibric acid, and the anticonvulsant and mood stabilizing drug, carbamazepine.

\section{METHOD}

\subsection{Reagents and materials}

All the drugs investigated (ibuprofen (CAS 15687-27-1), diclofenac sodium salt (CAS 1530779-6), naproxen (CAS 22204-53-1), ketoprofen (CAS 22071-15-4), clofibric acid (CAS 88209-7), and carbamazepine (CAS 298-46-4)) were supplied by Sigma-Aldrich (Gillingham, UK) as well as the derivatisation agent MTBSTFA (N-methyl-N-(tert-butyldimethyl-silyl) trifluoracetamide). The internal standards mecoprop (2-(4- chloro-2-methylphenoxy) propanoic acid) and d3-ibuprofen were obtained from Labor. Dr. Ehrenstorfer- Schäfers (Ausburg, Germany). Methanol, acetone, toluene, ethyl acetate, 30\% hydrogen peroxide, and $37 \%$ hydrochloric acid were of analytical grade and were provided by Merck (Darmstadt, Germany).

The water used for the experiment was either tap water or wastewater. The tap water contained chlorine which was removed by irradiating the water in the reactor at slow flow rate which correspond to an electric energy dose of $18 \mathrm{kWh} / \mathrm{m}^{3}$. The water was collected in $20 \mathrm{~L}$ containers. The wastewater was provided by the wastewater treatment plant, Centralna Čistilna Naprava Ljubljana. 


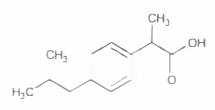

ibuprofen

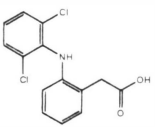

diclofenac

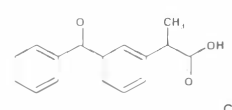

ketoprofen

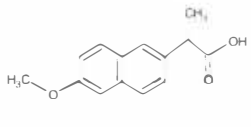

naproxen

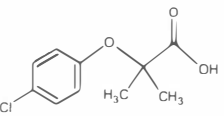

clofibric acid

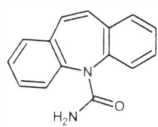

carbamazepine

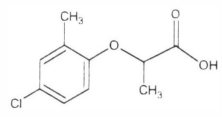

mecoprop (IS 1)

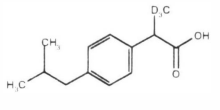

Ibuprofen-d3 (IS 2)

Figure 1. Six pharmaceuticals investigaded in this study and the internal standards.

\subsection{Bench scale reactor}

The treatments were carried out in a bench scale, flow through photoreactor (see Figure 2). The lamp (Bau47-700W, Scan Research A/S, Herning, Denmark) is located coaxial in the centre of the reactor. The UV-lamp was placed inside a quarts sleeve which is pumped with an inert gas to avoid ozone formation. The distance from the lamp to the inner side of the reactor is $5.7 \mathrm{~cm}$.

Figure 2 shows a photo of the experimental set-up and schematically drawing. The water was pumped from the plastic containers through a flowmeter and into the reactor at the bottom. A valve was used to adjust the flow rate. The samples for analysis were taken from the outlet after one retention time and from the containers (inlet concentration). The blind sample was taken before spiking and addition of hydrogen peroxide.

\subsection{Sample analysis}

The samples from the experiments with wastewater were filtered, first with glass pre-filter (GF 92, Schleicher \& Schuell, Dassel, Germany) then with $0.45 \mu \mathrm{m}$ membrane filter (Nylon 66 , Supelco, Bellefonte, PA, USA).

Both tap water and wastewater samples were acidified to $\mathrm{pH} 2.6$ with $\mathrm{HCl}$. The internal standards were added before solid phase extraction. For wastewater samples both mecoprop and ibuprofen- $\mathrm{d} 3$ were used while only mecoprop was used in tap water samples.

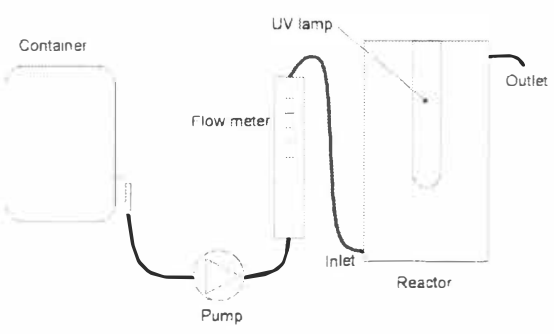

(a)

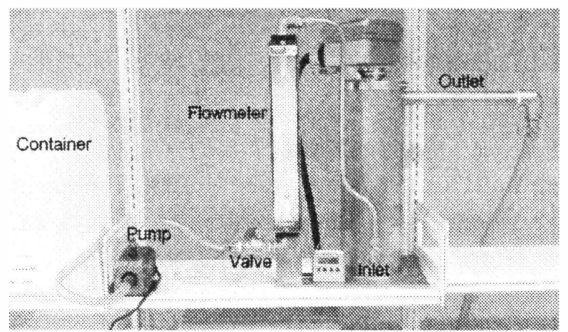

(1))

Figure 2. Diagram (a) and photo (b) of the experimental set-up. 
The SPE-columns were conditioned with $3 \mathrm{~mL}$ ethylacetat, $3 \mathrm{~mL}$ methanol, and $3 \mathrm{~mL}$ water, which was $\mathrm{pH}$ adjusted to 2.6. The samples were loaded on the SPE-columns at a flow rate of $2 \mathrm{~mL} / \mathrm{min}$, which afterwards were dried for 1 hour using vacuum. The SPE-columns were eluted with $3 \mathrm{~mL}$ ethylacetat, which were evaporated until approximately $0.5 \mathrm{~mL}$ under a stream of nitrogen and transferred to GC-vials and derivatised by adding $50 \mu \mathrm{L}$ of MTBSTFA. The GC-vials were then placed in an oven at $60^{\circ} \mathrm{C}$ for $60 \mathrm{~min}$.

The analysis of the derivatised drugs was preformed by GC-MSD on an HP 6890 instrument (Hewlett-Packard, Waldbron, Germany) fitted with a $30 \mathrm{~m} \times 0.25 \mathrm{~mm} \times 0.25 \mu \mathrm{m}$ HP-5 MS capillary column (Hewlett-Packard). The carrier gas was helium at a constant velocity of 37 $\mathrm{cm} / \mathrm{s}$. Injection was performed in the splitless mode at an injection temperature of $250^{\circ} \mathrm{C}$. The injection volume was $1 \mu \mathrm{L}$. The $\mathrm{GC}$ oven temperature was maintained at $100^{\circ} \mathrm{C}$ for $1 \mathrm{~min}$ then programmed at $30^{\circ} \mathrm{C} / \mathrm{min}$ to $190^{\circ} \mathrm{C}$, then at $3{ }^{\circ} \mathrm{C} / \mathrm{min}$ until $204^{\circ} \mathrm{C}$, followed by $30^{\circ} \mathrm{C} / \mathrm{min}$ to $245^{\circ} \mathrm{C}$, subsequently $5^{\circ} \mathrm{C} / \mathrm{min}$ until $265^{\circ} \mathrm{C}$, and finally $30^{\circ} \mathrm{C} / \mathrm{min}$ to $300^{\circ} \mathrm{C}$, which were hold for $1 \mathrm{~min}$ when drinking water samples were analysed and for $5 \mathrm{~min}$ for samples with wastewater effluent.

\subsection{Data treatment}

The treatment effectiveness is evaluated based on the Electrical Energy per Order (EEO) (unit $\mathrm{kWh} / \mathrm{m}^{3}$ ), which is defined as the electrical energy consumed per unit volume of water treated required for $90 \%$ removal of the investigated compound [5].

The normalised concentration of the investigated chemicals was plotted against the electrical energy dose. These plots were used for estimation of the electrical energy per order. The curves were fitted to the data using nonlinear regression.

$$
\log \left(\frac{C}{C_{1}}\right)=\frac{-1}{E E O} \cdot E E D
$$

; where $\mathrm{C}_{1}$ and $\mathrm{C}$ is the initial and the final concentration, respectively, EED is the electrical energy dose in $\mathrm{kWh} / \mathrm{m}^{3}$ and EEO is the electrical energy per order.

The regression is done by minimizing the sum-of-squares of the vertical distances of the data from the curve. The points were weighted by $1 / \mathrm{Y}^{2}$ (relative weighting) [6].

\section{RESULTS AND DISCUSSION}

\subsection{Removal rates}

Figure 3 shows the results from treatment of drugs in tapwater at different electrical energy dose. It is seen that $100 \%$ removal is obtained for four of the drugs for both treatment methods and at the most of the EED. Only at the lowest EED (where the water is exposed to the smallest UV dose), is the degradation of some of the compound not completely. There is no removal of carbamazepine when the tap water is exposed to the lowest UV dose without $\mathrm{H}_{2} \mathrm{O}_{2}$. Ibuprofen is only completely removed at the highest EED and shows a relationship between flow rate and removal. 

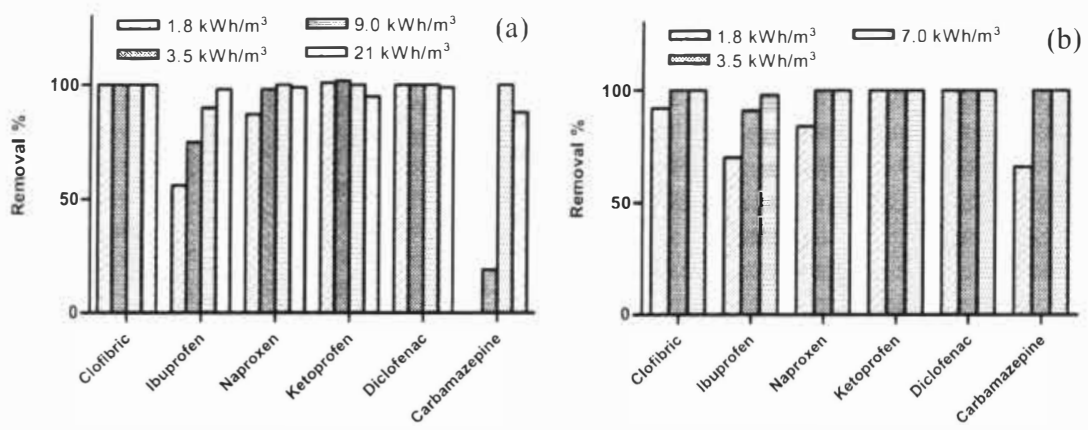

Figure 3. The removal of pharmaceuticals from tap water at different electrical energy dose by (a) photolysis and (b) $\mathrm{AOP}$ (initial concentration of $\mathrm{H}_{2} \mathrm{O}_{2}$ were $60 \mathrm{mg} / \mathrm{L}$ ). Initial concentration of the pharmaceuticals was $10 \mu \mathrm{g} / \mathrm{L}$.

The results from UV-treatment of the pharmaceutical spiked in wastewater effluent are shown in Figure 4. Ketoprofen and diclofenac were almost 100\% removed at the used EED, while the removal of clofibric acid, ibuprofen and naproxen shows a dependency of the EED. The analysis of carbamazepine was not successful in the wastewater effluent.

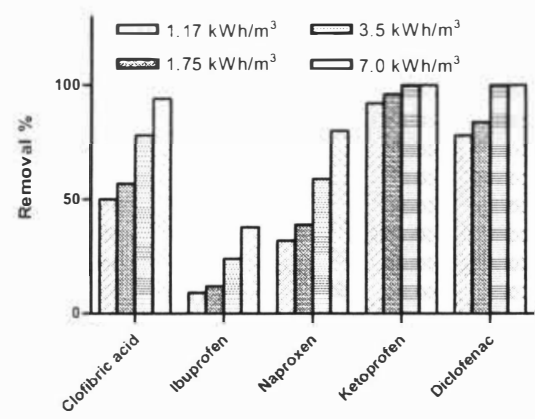

Figure 4. The removal of pharmaceuticals from wastewater effluent by photolysis at different electric energy dose. Initial concentration was $40 \mu \mathrm{g} / \mathrm{L}$.

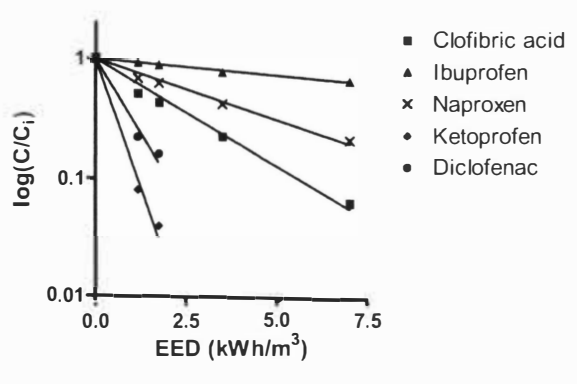

Figure 5. Regression lines for estimation of EEO for five pharmaceuticals treated by photolysis. 


\subsection{Energy efficiency}

Table $l$ shows the values of EEO for the pharmaceuticals. Less energy is requires to remove the pharmaceuticals from tap water than from wastewater effluent, which is as expected. The reason that the organic and inorganic compounds act as scavenger for radicals in wastewater effluent and will absorb or reflect part of the UV light.

It was found in the treatment experiments in tapwater that carbamazepine was the compound which was most difficult to remove (the highest EEO value) and that ketoprofen and diclofenac was totally removed at the used energy doses. The addition of $\mathrm{H}_{2} \mathrm{O}_{2}$ resulted in a lower value of EEO for carbamazepine and ibuprofen. The EEO which is estimated on basis of two points contains some uncertainty and the value would probably be a lower since complete removal was obtained for EED larger than $1.8 \mathrm{kWh} / \mathrm{m}^{3}$.

In the wastewater effluent ibuprofen is the compound that need the highest energy dose to remove $90 \%\left(\mathrm{EEO}=33.4 \mathrm{kWh} / \mathrm{m}^{3}\right)$ where naproxen and clofibric acid required $9.6 \mathrm{kWh} / \mathrm{m}^{3}$ and $5.5 \mathrm{kWh} / \mathrm{m}^{3}$, respectively. Ketoprofen and diclofenac needed considerable less energy than clofibric acid. Ibuprofen and naproxen is biodegradable [2] and will be removed in biologically treated wastewater. Therefore the relevant estimate of the needed treatment is the energy use for removal of clofibric acid which required $5.5 \mathrm{kWh} / \mathrm{m}^{3}$ for $90 \%$ removal.

\subsection{Absorption}

That naproxen was harder to degrade than diclofenac, comply with what Packer et al. [7] found in their investigation of photodegradation of four pharmaceuticals. It was found that clofibric acid is easier to remove than naproxen, which is in contrary to what Packer et al. [7] found. Packer et al. [7] did not degrade ibuprofen, which also is the most difficult to remove (see Table l).

The absorption spectra of naproxen, ibuprofen and clofibric acid are shown in Figure 6. It is seen that ibuprofen and clofibric acid only absorb light under $300 \mathrm{~nm}$ with a local maximum at approximately $225 \mathrm{~nm}$. Naproxen absorbs more light in the UV-range than ibuprofen and clofibric acid.

Table 1. The electrical energy per order $\left(\mathrm{kWh} / \mathrm{m}^{3}\right)$ with $95 \%$ confidence interval for the pharmaceuticals in tap water and wastewater by photolysis and advanced oxidation $160 \mathrm{mg}$ $\mathrm{H}_{2} \mathrm{O}_{2} / L$ ).

\begin{tabular}{|c|c|c|c|}
\hline & \multicolumn{2}{|c|}{ Tap water } & Wastewater effluent \\
\hline & $\begin{array}{c}\text { UV } \\
\mathrm{EEO}+95 \% \mathrm{Cl}\end{array}$ & $\begin{array}{c}\mathrm{UV} / \mathrm{H}_{2} \mathrm{O}_{2} \\
\mathrm{EEO} \pm 95 \% \mathrm{Cl}\end{array}$ & $\begin{array}{c}\text { UV } \\
\text { EEO }+95 \% \mathrm{CI}\end{array}$ \\
\hline Clofibric acid & - & $1.6^{\mathrm{a}}$ & $5.5 \pm 0.6$ \\
\hline Ibuprofen & $8.6 \pm 4.4$ & $3.7 \pm 0 . \Xi$ & $33.4 \pm 3.4$ \\
\hline Naproxen & $2.1 \pm 0.9$ & $2.2^{\mathrm{a}}$ & $9.6 \pm 1.1$ \\
\hline Ketoprofen & - & - & $1.2 \pm 0.3$ \\
\hline Diclofenac & - & - & $2.0 \pm 0.6$ \\
\hline Carbamazepine & $22.7 \pm 4.1$ & $3.7^{\mathrm{a}}$ & - \\
\hline
\end{tabular}




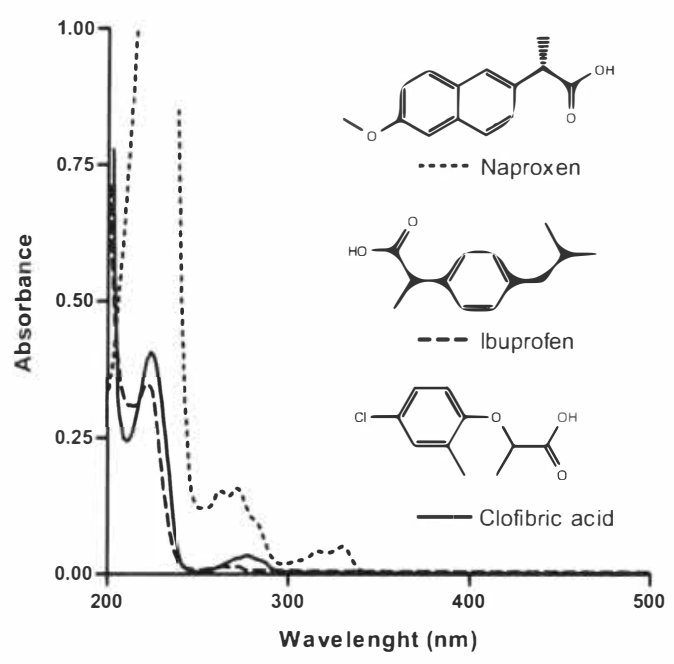

Figure 6. Absorption spectra and molecule structure of naproxen, ibuprofen, and clofibric acid.

Packer et al. [7] used natural sunlight as light source. Ozone in the atmosphere absorbs most of the radiation with a wavelength under approximately $280 \mathrm{~nm}$. If the light only have radiation with a wavelength above $280 \mathrm{~nm}$, degradation of ibuprofen and clofibric acid will not occur. It is understandable that Packer et al. [7] were unable to degrade ibuprofen as it does absorb minimal at wavelength above $240 \mathrm{~nm}$. The UV lamp used in this study did emit light with low wavelength and the probability of degrading clofibric acid and ibuprofen will be improved. It is not only the absorption spectra but also the quantum yield that influence the possibility to degrade a compound. The quantum yield of clofibric acid is likely to be higher than the one for ibuprofen since their absorption spectra are very much alike and clofibric acid is a lot easier to degrade than ibuprofen.

\section{ACKNOWLEDGEMENTS}

The Siemens Foundation, the EU Life project, APOP, and the Danish Research council project, DanEd, is gratefully acknowledged for economic support. Further, technical assistance with analysis by Silva Perko is recognized.

\section{REFERENCES}

[1] Clara,M., Strenn,B., Gans,O., Martinez,E., Kreuzinger,N., Kroiss,H., 2005. Removal of selected pharmaceuticals, fragrances and endocrine disrupting compounds in a membrane bioreactor and conventional wastewater treatment plants. Water Research 39 (19), 4797-4807. 
[2] Kosjek T., Heath E., Kompare B., 2007. Removal of pharmaceuticals residues in a pilot wastewater treatment plant. Analytical and Bioanalytical Chemistry. 387/4: 1379-1387

[3] Doll, T.E., Frimmel, F.H., 2003. Fate of pharmaceuticals--photodegradation by simulated solar UV-light. Chemosphere 52 (10), 1757-1769.

[4] Petrovic, M., Barceló,D., 2007. LC-MS for identifying photodegradation products of pharmaceuticals in the environment. Trends in Analytical Chemistry 26 (6), 486-493.

[5] Bolton, J. R., Bircher, K. G., Tumas, W., Tolman, C. A., 2001. Figures-of-merit for the technical development and application of advanced oxidation technologies for both electric- and solar-driven systems. Pure and Applied Chemistry 73 (4), 627-638.

[6] GraphPad Software Inc.. GraphPad Prism 5.0 - Regression Guide. http://www.graphpad.com/help/Prism5/, Septemper 18th, 2007.

[7] Packer, J. L., Werner, J. J., Latch, D. E., McNeill, K., Arnold, W. A., 2003. Photochemical fate of pharmaceuticals in the environment: Naproxen, diclofenac, clofibric acid, and ibuprofen. Aquatic Sciences 65 (4), 342-351. 